\title{
Genetic Dissection of Basal Resistance to Pseudomonas syringae pv. phaseolicola in Accessions of Arabidopsis
}

\author{
Alec Forsyth, ${ }^{1}$ John W. Mansfield, ${ }^{1}$ Nina Grabov, ${ }^{1}$ Marta de Torres, ${ }^{2}$ Eva Sinapidou, ${ }^{3}$ and Murray R. Grant ${ }^{2}$ \\ ${ }^{1}$ Division of Biology, Imperial College London, London, SW7 2AZ, U.K.; ${ }^{2}$ School of Biosciences, University of Exeter, Exeter, \\ EX4 4QD, U.K.; ${ }^{3}$ NAGREF, Institute of Plant Protection, Thermi 570 01, Thessaloniki, Greece
}

Submitted 26 February 2010. Accepted 12 July 2010.

\begin{abstract}
We have examined the genetics of nonhost resistance in Arabidopsis, using the bean pathogen Pseudomonas syringae pv. phaseolicola race 61448 A to probe accessions for natural variation in basal defense. Symptoms rarely developed in leaves of Niedersenz (Nd), some yellowing and occasional necrosis developed in Columbia (Col), whereas tissue collapse was observed in Wassilewskija (Ws) after inoculation by infiltration. Analysis of F2 progeny and recombinant inbred lines (RIL) from a cross between Col and $\mathrm{Nd}$ revealed a pattern of continuous symptom increase, indicating the operation of quantitative determinants of resistance. By mapping quantitative trait loci (QTL), significant linkage was determined for resistance (low symptom score) to markers on chromosome 4. Segregation in the F2 cross from $\mathrm{Nd} \times \mathrm{Ws}$ indicated the operation of two dominant genes for resistance, one of which was $F L S 2$ encoding the flagellin receptor. The requirement for $F L S 2$ to confer resistance was confirmed by transgenic experiments, and we showed that the response to $P$. syringae pv. phaseolicola was affected by $F L S 2$ gene dosage. Using RIL, the second locus was mapped as a QTL to a large interval on chromosome 1. Both FLS2 and the QTL on chromosome 1 were required for the highest level of resistance to bacterial colonization and symptom development in $\mathrm{Nd}$.
\end{abstract}

Remarkable morphological and physiological diversity exists among accessions of the model plant species Arabidopsis thaliana (Bomblies and Weigel 2007; Koorneef et al. 2004; Weigel and Nordborg 2005). For example, Werner and associates (2005) describe variation in natural flowering time, and Brosche and associates (2010) focus on differences in responses to abiotic stress. Variation between accessions has been utilized to understand the response of Arabidopsis to microbial challenge both in terms of gene for gene-mediated resistance to pathogens such as Pseudomonas syringae pvs. maculicola and tomato and the oomycete Hyaloperonospora arabidopsis (Banerjee et al. 2001; Debener et al. 1991; Holub 2007; Whalen et al. 1991) and also basal defenses activated by pathogen (or microbe)-associated molecular patterns (PAMPs) as

Current address for A. Forsyth: Department of Geographical and Life Sciences, Canterbury Christ Church University, Canterbury CT1 1QU, U.K.

Corresponding author: J. Mansfield; E-mail: j.mansfield@imperial.ac.uk; Telephone: +107771960519.

* The $\boldsymbol{e}$-Xtra logo stands for "electronic extra" and indicates that two supplementary tables and one supplementary figure are published online. reviewed by Boller and Felix (2009). Holub (2007), in a perceptive discussion of natural variation and innate immunity, emphasizes the role of resistance $(R)$ gene diversity in the ecology of adapted pathogens, such as Hyaloperonospora parasitica sp. arabidopsis. Several studies have demonstrated quantitative differences in the susceptibility of accessions to $P$. syringae pv. tomato and also to $P$. syringae pv. maculicola, and quantitative trait loci (QTL) partially controlling differentials have been identified (Fan et al. 2008; Kover and Schaal 2002; Perchepied et al. 2006). Differentials have also been reported following challenge with Xanthomonas campestris pv. campestris (Buell and Somerville 1997). There are striking examples of variation in responses to PAMPs as well. For example, the Wassilewskija (Ws) accession fails to respond to flagellin, one of the major bacterial PAMPs to activate innate immunity in both plants and animals. The failure of Ws-3 to respond to the 22-amino acid consensus flagellin peptide (flg22) is due to a mutation introducing a stop codon within the FLS2 gene before the region encoding the kinase domain of the protein (Boller and Felix 2009; Zipfel et al. 2004).

The absence of functional FLS2 from Ws-3 has been reported to render the accession more susceptible to colonization by the Arabidopsis pathogens $P$. syringae pvs. tomato and maculicola and also to the RW60 strain of the bean pathogen $P$. syringae pv. phaseolicola when the bacterium expresses the effector protein AvrPtoB (de Torres et al. 2006; Zipfel et al. 2004). Intriguingly, the enhancement of virulence of RW60 by the effector is also observed but to a much lesser extent in Col-0, which has a fully functional FLS2 receptor. By contrast, Niedersenz (Nd-1) remains fully resistant to RW60 with or without AvrPtoB (de Torres et al. 2006). The decrease in resistance to pathovars of $P$. syringae conferred by lack of flagellin perception in Ws-3 is only partial because of the activity of receptors for other PAMPs, such as the elongation factor and chitin receptors (EFR and CERK1, respectively) (Gimenez-Ibanez et al. 2008; Zipfel et al. 2006).

We are investigating the role of PAMP perception in nonhost resistance, using the bean pathogen $P$. syringae pv. phaseolicola race 6 1448A to probe Arabidopsis accessions for natural variation in basal defense. Arabidopsis is normally considered a nonhost for strains of $P$. syringae pv. phaseolicola (Ham et al. 2007; Kang et al. 2003), but we found clear differences in the ability of $P$. syringae pv. phaseolicola to colonize and cause symptoms in the common accessions Col-0, Col-3, Col$5, \mathrm{Nd}-1$, and Ws-3. Analysis of recombinant inbred lines (RIL) developed from crosses of Col-3 and Col-5 with Nd-1 (Werner et al. 2005) and Ws-3 with Nd-1 (generated in this study) have revealed heritable differences in susceptibility that correspond 
to QTL for resistance in addition to FLS2. A second locus, which we refer to as basal resistance to $P$. syringae pv. phaseolicola 1 (BRF1), was identified as a QTL required with FLS2 for the high level of resistance characterized in Nd-1.

\section{RESULTS}

\section{Differentiation between accessions}

in their reaction to $P$. syringae pv. phaseolicola 1448 A.

Inoculation of $P$. syringae pv. phaseolicola $1448 \mathrm{~A}$ at high concentrations (more than $2 \times 10^{8}$ cells $\mathrm{ml}^{-1}$ ) rarely caused any symptom development in the Nd-1 accession, even after incubation for 5 days. By contrast, significant collapse was observed in the partially susceptible Ws-3, whereas Col-0 (and Col-3 or Col-5) proved intermediate, with some yellowing and, occasionally, very patchy tissue collapse (Fig. 1A through C). Leaves of $\mathrm{Nd}-1$ and $\mathrm{Col}$ produced callose after treatment with $P$. syringae pv. phaseolicola flagellin peptide, whereas Ws-3 did not (Fig. 1D through F). The reactions in Arabidopsis contrasted with the differential virulence of the pathovars to bean (Fig. $1 \mathrm{G}$ through I). Although P. syringae pv. phaseoli-

\section{Symptoms and callose deposition}
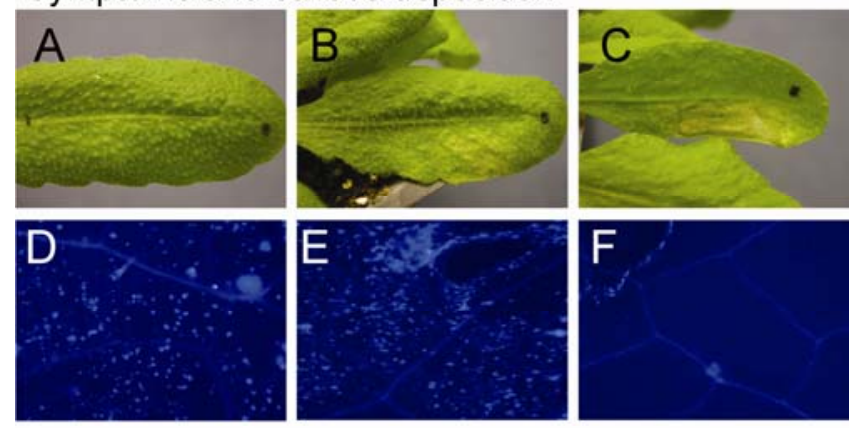

\section{DC3000 and Pph compared}
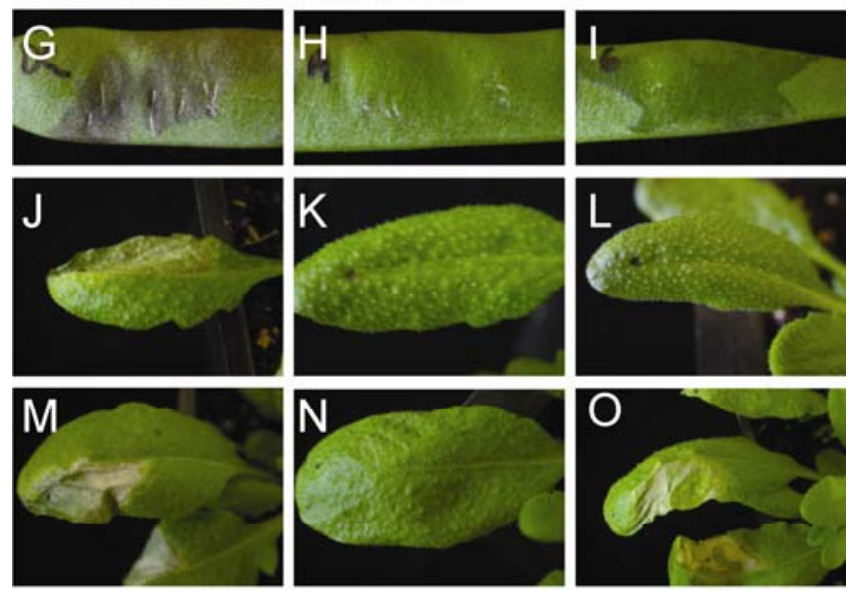

$\mathrm{P}$ Bacterial multiplication in $\mathrm{Nd}$ and $\mathrm{Ws}$

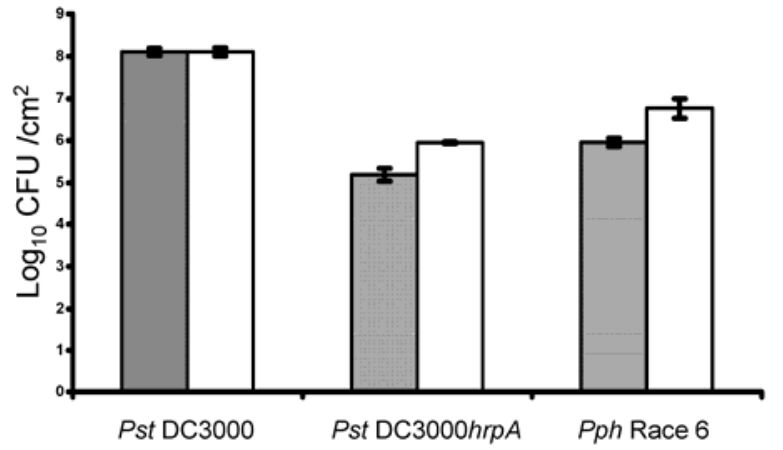

cola multiplied in Ws-3 leaves at a much faster rate than a hrp mutant of the Arabidopsis pathogen P. syringae pv. tomato DC3000, the strain was clearly far less virulent than wild -type DC3000 (Fig.1J through P).

Ws accessions lack the flagellin sensor FLS2, and we examined the contribution of the PAMP receptor in resistance to $P$. syringae pv. phaseolicola, using gene knockouts in Col-0 and ectopic expression of FLS2 in Ws-3. The differential symptom production in Nd-1, Col-0, and Ws-3 was reflected by proportional increases in bacterial numbers within challenged leaves. Mutation of FLS2 in Col-0 allowed multiplication to the levels found in Ws-3. The transgenic expression of FLS2 in Ws-3 restricted bacterial colonization but not to the low levels of multiplication observed in wild-type Nd-1 (Fig. 2). We also examined the effect of replacing the FLS2 gene in $\mathrm{Nd}-1$ with the fls2 allele from Ws-3, using a series of backcrosses to introgress the region on chromosome 5 of Ws-3 into Nd- 1 . The resultant $\mathrm{Nd}:$ :fls2 lines responded to $P$. syringae pv. phaseolicola in the partially susceptible manner observed with Ws-3 (Supplementary Fig. S1), indicating the clear involvement of FLS2 in nonhost resistance.

\section{Analysis of crosses between Col and Nd.}

Lesion development was analyzed in detail in F2 progeny, using a 12-point symptom index. Scores were compared between experiments, using wild-type Col-5 and Nd-1 as internal controls. Normalized data were produced by expressing symp-

Fig. 1. Symptoms caused by, and growth of Pseudomonas syringae pv. tomato (DC3000) and P. syringae pv. phaseolicola (Pph) strains in bean and Arabidopsis. Representative images are presented, the inoculations were repeated throughout the experiments as internal controls (at least 100 repetitions). Very little variation was observed in bean or in Arabidopsis challenged with DC3000. The response of Arabidopsis to P. syringae pv. phaseolicola was more variable, but the reactions shown were found in more than $95 \%$ of sites. On occasions less collapse was observed than as shown in Ws, and more symptoms occurred in both Col and Nd leaves. The clear differential between accessions was, however, always observed. A, B, and C, Symptoms in Arabidopsis leaves 3 days after inoculation with a bacterial suspension of $P$. syringae pv. phaseolicola race $61448 \mathrm{~A}$ (optical density at $600 \mathrm{~nm}\left[\mathrm{OD}_{600}\right]=0.05$, approximately $5 \times 10^{7} \mathrm{CFU} \mathrm{ml}{ }^{-1}$ ). A, Nd-1, no obvious symptoms, B, Col-0, a clear yellowing of the inoculated area has developed, $\mathbf{C}, \mathrm{Ws}-3$ inoculated with $P$. syringae pv. phaseolicola shows collapse of the infiltrated area, D, E, and F, leaves treated with $P$. syringae pv. phaseolicola flg22 peptide $(100 \mu \mathrm{M})$ for $24 \mathrm{~h}$ and stained for callose with $0.05 \%$ aniline blue in $50 \mathrm{mM}$ phosphate buffer, $\mathrm{pH}$ 8.0. D and E, In Nd-1 and Col-0 respectively, callose deposits are seen as fluorescent spots, F, Ws-3 treated with flg22 does not accumulate callose. $\mathbf{G}, \mathbf{H}$, and I, Bean pods (cv. Tendergreen) syringe-inoculated with $P$. syringae pv. tomato wild type causing the hypersensitive response, $P$. syringae pv. tomato hrpA mutant (no reaction) and $P$. syringae pv. phaseolicola (water-soaked symptoms), respectively. $\mathbf{J}, \mathbf{K}$, and $\mathbf{L}$, Comparison of symptoms in Nd-1 caused by $P$. syringae pv. tomato wild-type, $P$. syringae pv. tomato hrpA mutant, and $P$. syringae pv. phaseolicola, respectively, 3 days after inoculation with bacterial suspensions $\left(\mathrm{OD}_{600}=0.05\right.$, approximately $5 \times 10^{7} \mathrm{CFU} / \mathrm{ml}, 10 \mathrm{mM} \mathrm{MgCl}_{2}$ ). $\mathbf{J}$, P. syringae pv. tomato wildtype causing collapse of the inoculated area. $\mathbf{K}, \mathrm{Nd}-1$ inoculated with $P$. syringae pv. tomato hrpA develops no obvious symptoms. L, Nd-1 inoculated with $P$. syringae pv. phaseolicola race 6 1448A also develops no obvious symptoms. $\mathbf{M}, \mathbf{N}$, and $\mathbf{O}$, Same as $\mathrm{J}, \mathrm{K}$, and $\mathrm{L}$, but inoculation into leaves of Ws-3. Note that both $P$. syringae pv. tomato $(\mathrm{M})$ and $P$. syringae pv. phaseolicola $(\mathrm{O})$ cause some tissue collapse but no symptoms develop after inoculation with the hrp mutant $(\mathrm{N})$. P, Bacterial populations in Arabidopsis leaf tissue recovered 2 days after inoculation from plants inoculated with $P$. syringae pv. tomato DC3000, P. syringae pv. tomato DC3000 hrpA, and $P$. syringae pv. phaseolicola race $61448 \mathrm{~A}\left(\mathrm{OD}_{600}=\right.$ 0.05 , approximately $5 \times 10^{7} \mathrm{CFU} \mathrm{ml}^{-1}, 10 \mathrm{mM} \mathrm{MgCl}_{2}$ ). Gray bar $=\mathrm{Nd}-1$, open bar $=$ Ws -3 . Means \pm standard error of the means are given from six replicates. Population counts for $P$. syringae pv. phaseolicola in Ws-3 and Nd-1 were repeated 20 times with similar results. 
tom scores as the ratio of the mean $\mathrm{Nd}-1$ score for each experiment. The development of yellowing and patchy necrosis was progressive, and similar rank orders were obtained three and five days after inoculation. The range of scores recorded is shown in Figure 3A.

Analysis of 90 RIL generated a similar pattern of increasing symptom development, indicating the operation of quantitative determinants of resistance (Fig 3B). Interestingly, certain RIL were identified as more susceptible than Col-5 and others more resistant than Nd-1 (Fig. 3B). Using the RIL provided plant material to allow bacterial multiplication to be measured by colony counting. Analysis of selected RIL confirmed that symptom scores were positively correlated with bacterial populations. However, within lines with low average scores, the occasional high-scoring lesion contained high numbers of bacteria (Supplementary Table 1).

Mapping QTL was achieved with a combination of markers and published data for the set of RIL (Werner et al. 2005). The strongest linkage was determined for resistance (low symptom score) to markers on chromosome 4, with high levels of significance recorded using either Kruskal-Wallis or interval mapping-based assessments (data not shown). The logarithm of odds (LOD) scores from interval mapping are presented in Figure 4. The main QTL was located in a large region containing numerous genes of potential significance to basal defense, notably BAK1 (At4g33430). However, sequence analysis of BAK1 PCR products from Nd-1 revealed no coding differences in this gene between $\mathrm{Nd}$ and $\mathrm{Col}$, and BAK1 mutants of Col-0 were found not to be any more susceptible than Col- $0 \mathrm{wt}$ (data not shown). We conclude that BAK1 is not directly involved in the differential observed between $\mathrm{Nd}$ and Col accessions. One or more unidentified genes mapping to this interval may be responsible for the difference in susceptibility. Additional minor QTL were suggested on other chromosomes.
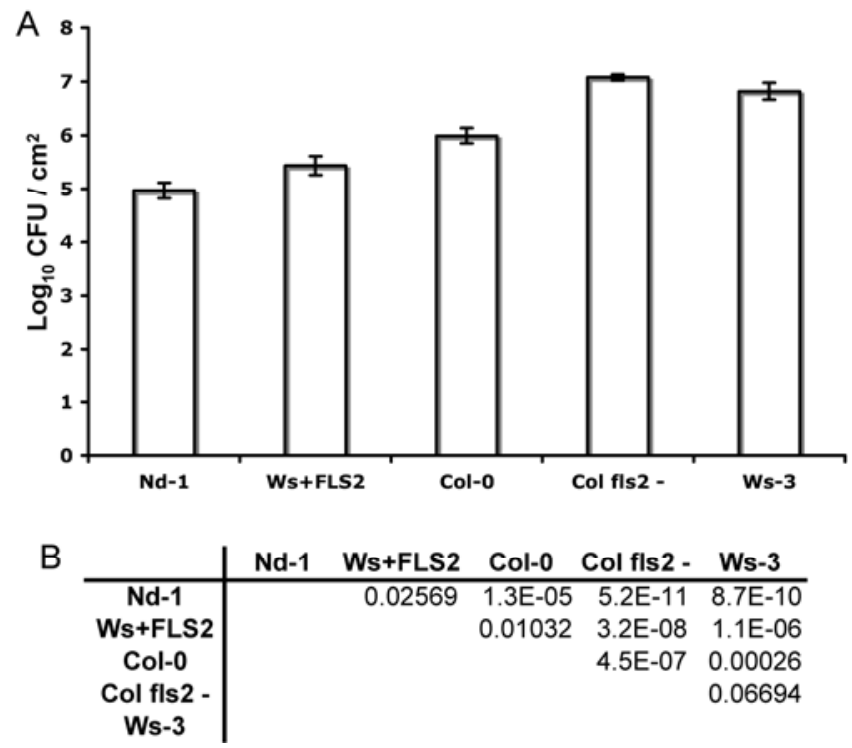

Fig. 2. The effect of FLS2 on the growth of Pseudomonas syringae pv. phaseolicola race 6 1448A in different Arabidopsis lines. A, Bacterial populations in Arabidopsis leaf tissue recovered 3 days after inoculation from plants inoculated with $P$. syringae pv. phaseolicola race $61448 \mathrm{~A}$ $\left(\mathrm{OD}_{600}=0.05\right.$, approximately $\left.5 \times 10^{7} \mathrm{CFU} \mathrm{m}{ }^{-1}\right)$ Arabidopsis lines inoculated were Nd-1, Ws-3 transgenic expressing FLS2 (Ws+FLS2), Col-0, an fls2 mutant of Col-0 (Col fls2-), and Ws-3. Data are means from six replicates \pm standard error of the means. B, Pair-wise statistical comparison of bacterial population means, showing $P$ values calculated for Student's $t$ tests (one-tailed, assuming unequal variance). All means are significantly different from each other at $P=0.05$, except for Ws-3 and Col fls2-, the two lines of Arabidopsis lacking a functional copy of $F L S 2$.
Analysis of crosses between Ws and Nd.

F1 to F4. There were very clear differences between wildtype Nd-1 and Ws-3 (Fig 1). The F1 progeny tested were as resistant as $\mathrm{Nd}-1$, although lesion development was slightly more pronounced on older leaves (data not shown).

Clear segregation for resistance was observed in F2 populations. Defining resistance or susceptibility as producing symptoms within the range observed in wild-type Nd-1 or Ws-3, respectively, after high bacterial inoculation, clearly susceptible F2 segregants could be identified by the collapse of inoculated tissue. Segregation did not fit the 3:1 resistant/susceptible ratio expected if the phenotype was controlled by a single gene (Table 1). Resistance better fitted a 9:7 ratio (resistant/susceptible), indicative of two genes required for the Nd-1 phenotype (Table 1). Because of the likely contribution of FLS2 to the resistance of Nd-1, we also tested progeny for their response to the flagellin peptide, recording induction of callose deposition. Segregation for callose induction occurred in the expected 3:1 ratio, indicating inheritance of the FLS2 allele, but some plants that responded to flg22 remained susceptible to $P$. syringae pv. phaseolicola (Table1). Our results indicated that $\mathrm{Nd}-1$ contains a second gene, which we propose to name basal resistance to $P$. syringae pv. phaseolicola 1 (BRF1), in addition to FLS2, which is required for the strong, symptomless resistance phenotype.

Analysis of the role of $F L S 2$ was extended to examine the effect of gene dosage among the susceptible progeny that responded to flg22. Analysis of plants with cleaved amplified polymorphic sequence (CAPS) markers specific for the Nd-1 and Ws-3 alleles of FLS2 indicated a clear distortion of expected segregation, so that far fewer plants homozygous for Nd-1 FLS2 were observed to be susceptible than was expected (Table 1). The low numbers of susceptible segregants homozygous for FLS2 suggested that homozygous FLS2 plants may be partially able to compensate for the absence of $B R F 1$.

We also examined F3 and F4 progeny, selecting F2 plants for breeding that had a range of symptom scores and reactions

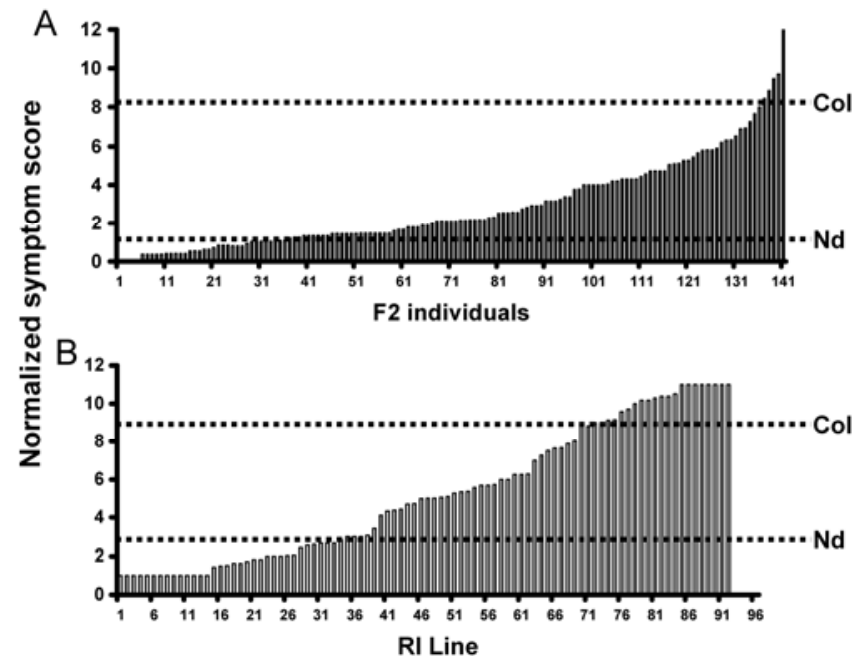

Fig. 3. Segregation of Pseudomonas syringae pv. phaseolicola race 6 1448A symptoms in populations derived from crosses between $\mathrm{Nd}-1$ and Col. Symptom scores normalized as a ratio of inoculated Nd-1 plants. Dashed line shows the average symptom score for Nd-1 and Col-0 in each experiment. $0=$ no symptoms, $12=$ tissue collapse. A, Segregation of symptoms in an F2 cross between Nd-1 and Col-0. Four leaves of 142 F2 segregants were inoculated and scored. An average leaf score was normalized to symptom scores derived from inoculated Nd-1 plants. B, Segregation of symptoms in 92 recombinant inbred lines generated between Nd-1 and Col-3/Col-5. Four leaves per plant of eight plants per line were inoculated and scored. Symptom scores were normalized to scores derived from inoculated Nd-1 plants 5 days after inoculation. 
to flg22. Most progeny gave the phenotypes expected from our $F L S 2+B R F 1$ hypothesized requirement for strong resistance, and all plants without a functional copy of FLS2 were susceptible. However, it became clear that certain plants with FLS2 but scored as susceptible in F2 progeny, and therefore theoretically lacking $B R F 1$, gave rise to resistant progeny. As potential misscoring of individual plants would hamper attempts to map $B R F 1$, we decided to extend our analysis using RIL.

RIL. In total, 120 F10 RIL from the Ws-3, Nd-1 cross (termed our WRIN lines) were screened with $P$. syringae pv. phaseolicola. We first reassessed our inoculation procedures and decided to score interactions using both symptom development and population counts. Symptoms were recorded daily, using three inoculum concentrations $(0.01,0.05$, and 0.3 optical density) and population counts determined with the lowest concentration three days after inoculation, when differentiation between bacterial numbers in Nd-1 and Ws-3 parents was typically 100-fold. Good correlations were recorded between the symptom scores and population counts, although the relationship varied depending on the day after inoculation and chosen inoculum dosage as shown in Figure 5. Accumulating data from 1, 2, and 3 days after inoculation with the three inocula and including the population count gave 10 phenotype scores to submit to QTL analysis.

We generated 44 CAPS markers, distributed evenly across the Nd-1 and Ws-3 genomes, including markers in specific genes, such as $\mathrm{NHOl}$, which was found to be polymorphic (Supplementary Table S2). QTL analysis was applied, using each of the 10 phenotype scores and a combination of all phenotypes. The most significant QTL emerged from the later

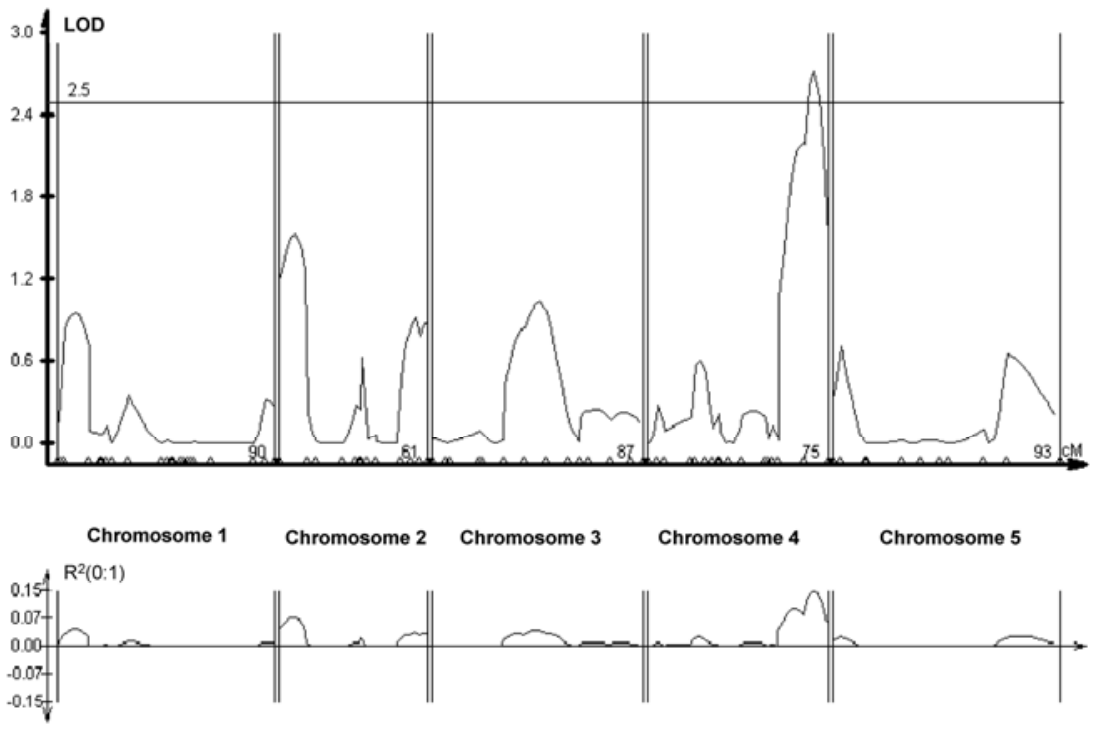

Fig. 4. Quantitative trait loci (QTL) map based on symptoms caused by Pseudomonas syringae pv. phaseolicola in Nd-Col recombinant inbred lines 5 days after inoculation. Logarithm of odds (LOD) scores and a calculated threshold for statistical significance of LOD $=2.5$ are displayed across each chromosome. Small triangles indicate marker positions shown in centimorgans. The proportion of variance attributable to each QTL is displayed on the lower graph. A QTL accounting for $15 \%$ of symptom variation was identified on chromosome 4

Table 1. Segregation of resistance and susceptibility (tissue collapse) to Pseudomonas syringae pv. phaseolicola and production of callose, after treatment with flg 22 peptide in $\mathrm{F} 2$ progeny from the Nd- $1 \times$ Ws -3 cross

\begin{tabular}{|c|c|c|c|c|}
\hline Feature & Predicted ratio & Observed segregation & Calculated chi square & $\begin{array}{l}\text { Maximum chi square } \\
\text { value for } P=0.05\end{array}$ \\
\hline \multicolumn{5}{|c|}{ Segregation of resistance as a single gene trait ${ }^{\mathrm{a}}$} \\
\hline Resistant & 3 & 111 & 19.05 & 3.84 \\
\hline Susceptible & 1 & 71 & & \\
\hline \multicolumn{5}{|c|}{ Segregation of resistance as a two gene trait ${ }^{\mathrm{a}}$} \\
\hline Resistant & 9 & 111 & 2.64 & 3.84 \\
\hline Susceptible & 7 & 71 & & \\
\hline \multicolumn{5}{|c|}{ Segregation of callose production after flg 22 treatment ${ }^{\mathrm{b}}$} \\
\hline Callose & 3 & 134 & 0.18 & 3.84 \\
\hline No callose & 1 & 48 & & \\
\hline \multicolumn{5}{|c|}{ Segregation of resistance and response to flg 22 treatment $\mathrm{t}^{\mathrm{c}}$} \\
\hline Resistant & 9 & 111 & 4.49 & 5.99 \\
\hline Susceptible with callose & 3 & 23 & & \\
\hline Susceptible no callose & 4 & 48 & & \\
\hline \multicolumn{5}{|c|}{ Zygosity of $F L S 2$ in selected susceptible F2 progeny ${ }^{\mathrm{d}}$} \\
\hline Heterozygous & 2 & 63 & 5.26 & 3.84 \\
\hline Homozygous & 1 & 17 & & \\
\hline
\end{tabular}

a The resistance and susceptibility ratio does not fit the expected 3:1 ratio, but rather, a 9:7 ratio, indicative of control by two dominant genes.

${ }^{\mathrm{b}}$ Callose production in response to flagellin segregates as expected as a single gene controlled trait.

c The 9:7 ratio predicts, accurately, the presence of some susceptible plants carrying $F L S 2$ and responding to flg22.

d The proportion of heterozygous to homozygous FLS2 progeny in plants selected as susceptible did not fit the expected 2:1 ratio. Homozygosity of FLS2 appeared to compensate in part for the possible absence of the second predicted gene for resistance. 
timepoints of symptom scoring as well as population counts. Our first analysis included all RIL and clearly demonstrated the major importance of FLS2 (At5g46330) as a determinant of resistance, using each phenotype. For example, as shown in Figure 6 , the strong linkage to chromosome 5 dominated the analysis. Remarkably, significant linkage to FLS2 was recorded even with symptom scores recorded on the first day after infiltration from the lowest concentration of inoculum. There was, however, clear indication of an additional putative QTL on chromosome 1 that was most significant from population counts (Fig. 7).

In order to remove the overriding effect of $F L S 2$, we carried out a second analysis, using only those RIL (59) containing FLS2 (therefore, no segregation for this marker). Using this approach, the linkage of resistance to chromosome 1 was much more robust (Fig. 8), particularly with the population data (Fig. 8). The QTL on chromosome 1 accounted for about $30 \%$ of the variation in susceptibility recorded.

\section{DISCUSSION}

Arabidopsis is considered a nonhost to $P$. syringae pv. phaseolicola. Unlike interactions between many other plants and pathogenic bacteria (Alfano and Collmer 1966), the resistance of Arabidopsis to the bean pathogen does not involve the hypersensitive reaction (HR) (Ham et al. 2007; Soylu et al. 2005). The failure of $P$. syringae pv. phaseolicola to trigger the HR in Arabidopsis is surprising, given the numbers of effector proteins encoded in the $P$. syringae pv. phaseolicola genome (Bock et al. 2008; Cunnac et al. 2009; Joardar et al. 2005). Strains of $P$. syringae pv. phaseolicola are capable of delivering effectors from other bacteria, such as AvrPpiA and AvrRpt2, and causing the HR in Arabidopsis (Soylu et al, 2005; Yu et al. 1993). It is possible that none of the effectors encoded by $P$. syringae pv. phaseolicola is recognized by matching $R$-gene complexes to trigger immunity. However, an alternative explanation may be that the responses of accessions such as $\mathrm{Nd}$ and Col to PAMPs from $P$. syringae pv. phaseolicola is so rapid that endogenous effector delivery may be blocked. In the absence of the HR, nonhost resistance has been linked to rapid changes in the plant cell wall as an expression of basal or PAMP-triggered immunity (Bestwick et al. 1995; Soylu et al. 2005). Our research has shown that the quality of basal defense varies between accessions and is an inheritable trait linked to newly defined QTL on chromosomes 1 and 4 in the highly resistant Nd-1 ecotype. However, FLS2 encoding the flagellin receptor has emerged as the most significant determinant of nonhost resistance to $P$. syringae pv. phaseolicola.

Previous attempts to dissect nonhost resistance to $P$. syringae pv. phaseolicola have utilized random mutagenesis, (Kang et al. 2003; Lu et al. 2001) or analysis of mutations in genes known to influence plant defenses in Col-0 (Ham et al. 2007). The former approach led to the identification of $\mathrm{NHOl}$ (At1g80460, predicted to encode a glycerol kinase) as a major factor in the restriction of bacterial multiplication. Ham and associates (2007) revealed that nonhost resistance was, as they termed, a "multilayered" process controlled by several genes regulating different signaling pathways and mechanisms of resistance. They found that mutations in individual genes, pmr4, pad4, nprl did not affect the ability of $P$. syringae pv. phaseolicola to multiply in Col-0 leaves, but the double mutant pad4/pmr4 did allow enhanced colonization, particularly if $P$. syringae pv. phaseolicola expressed the effector HopM1. Of the genes examined by Kang and associates (2003) and Ham and associates (2007), none is located in the region of chromosome 1 highlighted by our analyses. The QTL located to chromosome 4 was partly responsible for the differentiation observed between $\mathrm{Nd}-1$ and $\mathrm{Col}$ and this falls close to pmr4-1 (At4g03550). As both of these accessions show rapid callose deposition after treatment with bacteria or flagellin, it seems unlikely that polymorphism in pmr4 is the cause of the difference in susceptibility to $P$. syringae pv. phaseolicola.

Both Col and $\mathrm{Nd}$ carry functional alleles of the flagellin receptor FLS2, but their reaction to $P$. syringae pv. phaseolicola clearly differs. A significant contributor to the differentiation between the two accessions is the QTL identified on chromosome 4 , accounting for $15 \%$ of the variation in symptom formation. We found no evidence that potential differences in the efficiency of flagellin perception due to polymorphism in the FLS2 protein in Nd-1 and Col influence the reaction to $P$. syringae pv. phaseolicola. We assessed the resistance of the RIL based solely on the appearance of symptoms (mainly degrees of yellowing) at infiltration sites. The appearance of such lesions was correlated with increased multiplication of bacteria
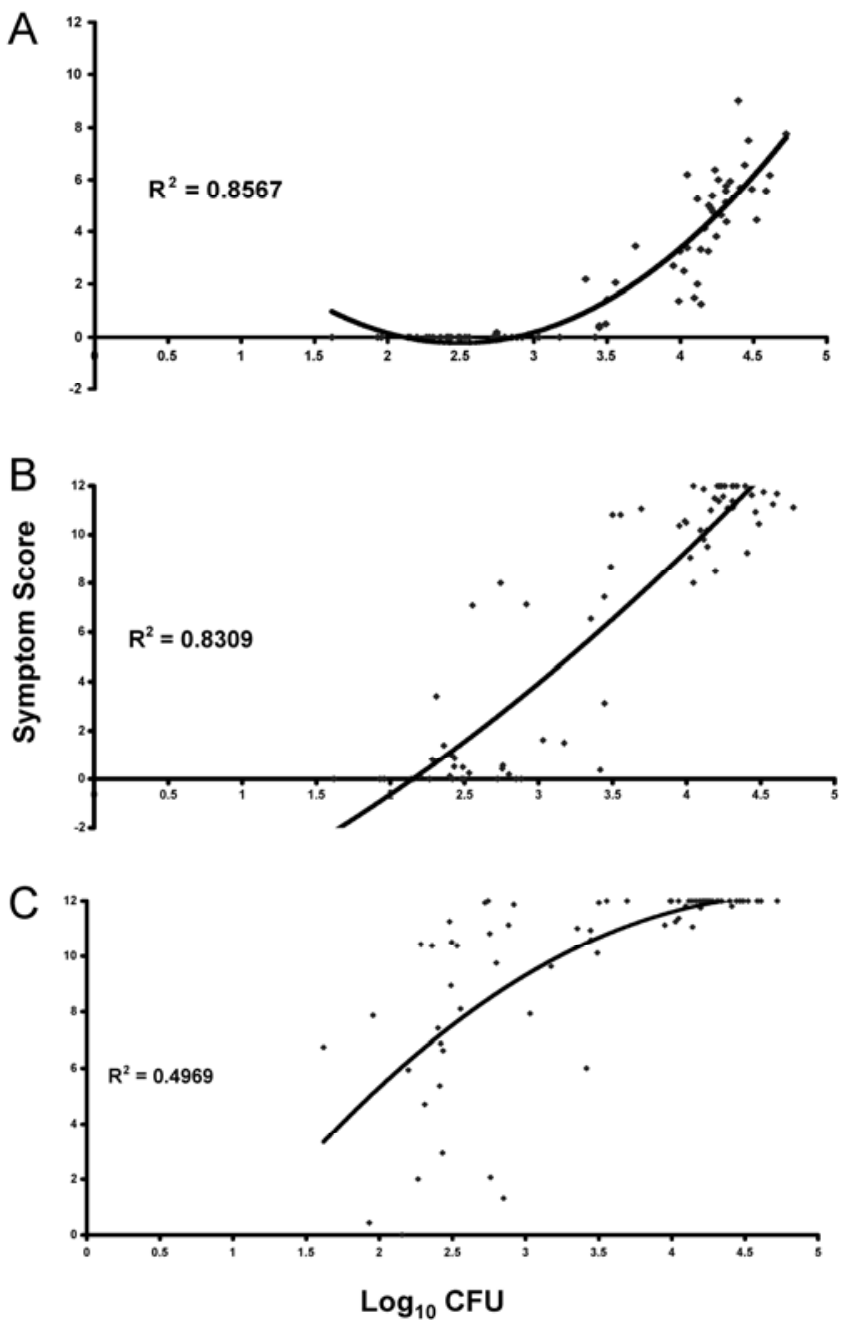

Fig. 5. Relationships between symptom phenotype (based on a 12-point symptom scale) and bacterial population $\left(\log _{10}\right)$ CFU in WRIN lines (recombinant inbred lines from the Ws-3, Nd-1 cross) inoculated with Pseudomonas syringae pv. phaseolicola race 6 1448A. Leaves were infiltrated with suspensions of bacteria at different optical density at $600 \mathrm{~nm}\left(\mathrm{OD}_{600}\right)$ levels and were examined at intervals after inoculation. A, WRIN lines infiltrated with $P$. syringae pv. phaseolicola at $\mathrm{OD}_{600}=0.01$ scored 2 days after inoculation, B, WRIN lines infiltrated with $P$. syringae pv. phaseolicola at $\mathrm{OD}_{600}=0.05$ scored 2 days after inoculation, C, WRIN lines infiltrated with $P$. syringae pv. phaseolicola at $\mathrm{OD}_{600}=0.3$ scored 3 days after inoculation. Note that susceptible leaves had collapsed after 3 days following inoculation with the highest inoculum, leading to clustering of the symptom data. 
and may reflect differences in the speed of activation of basal defenses between Nd and Col. Significant numbers of the RIL were more resistant or more susceptible than the parental Nd-1 or Col accessions, respectively, indicating the operation of transgressive segregation and the presence of components for susceptibility in Nd masked by the strong QTL for resistance.

The most striking feature of our analysis of the $\mathrm{Ws}$ and $\mathrm{Nd}$ crosses is the dominance of FLS2 as a determinant of the outcome of the interaction between $P$. syringae pv. phaseolicola and Arabidopsis. The flagellin receptor accounted for up to $70 \%$ of the variability between WRIN lines. However, it is clear that the strong, symptomless resistance of $\mathrm{Nd}$ requires a second locus that we have named BRF1. Removing FLS2 from the QTL analysis mapped the potential $B R F 1$ QTL to a large interval on chromosome 1. Linkage to the FLS2 locus probably accounts for the strength of the LOD score for other regions on chromosome 5 (Fig. 8).

The Nd-1 accession clearly requires $B R F 1$ in addition to $F L S 2$ for the full activation of high-level basal resistance. Not only functional FLS2 but also BRF1 appear to be absent from Ws-3. The introduction of FLS2 into Ws-3 does not increase its resistance to that found in Nd-1. The operation of the FLS2based sensing system is known to require several other proteins, including BAK1, which interacts directly with FLS2 in the presence of flg22 (Boller and Felix 2009). Although there is currently no evidence for its function, we speculate that BRF1 acts as an enhancer of flagellin perception. It seems unlikely to operate as an additional PAMP receptor because Nd-1 carrying an introgressed nonfunctional allele of fls 2 was as susceptible as Ws-3. A role for BRF1 in downstream signaling, perhaps operating within the mitogen-activated protein kinase cascade or modulating protein phosphorylation known to be activated after flagellin perception, remains a possibility (He et al. 2006; Shan et al. 2008). Having identified a potential locus for BRFI on chromosome 1, our attention now is focused on cloning $B R F 1$ to allow its function in PAMP recognition to be determined.

\section{MATERIALS AND METHODS}

Plants.

Arabidopsis plants were grown under short days (10-h illumination, $23^{\circ} \mathrm{C}$ days, and $21^{\circ} \mathrm{C}$ nights) and $60 \%$ relative humidity. Eight-week-old seedlings were used for inoculation experiments. A series of RIL were generated between a cross of Ws-3 and Nd-1. F2 progeny were taken to F10 generation by singleseed descent to produce 300 WRIN lines, of which 120 were used in experiments. Nd-Col RIL were obtained from the Arabidopsis Stock Centre, Nottingham, stock set CS1696. Transgenic lines were described by de Torres and associates (2006).

\section{Bacterial inoculations and flagellin infiltration.}

Stocks of Psuedomonas syringae strains were maintained on King's B medium agar plates supplemented with rifampicin (50

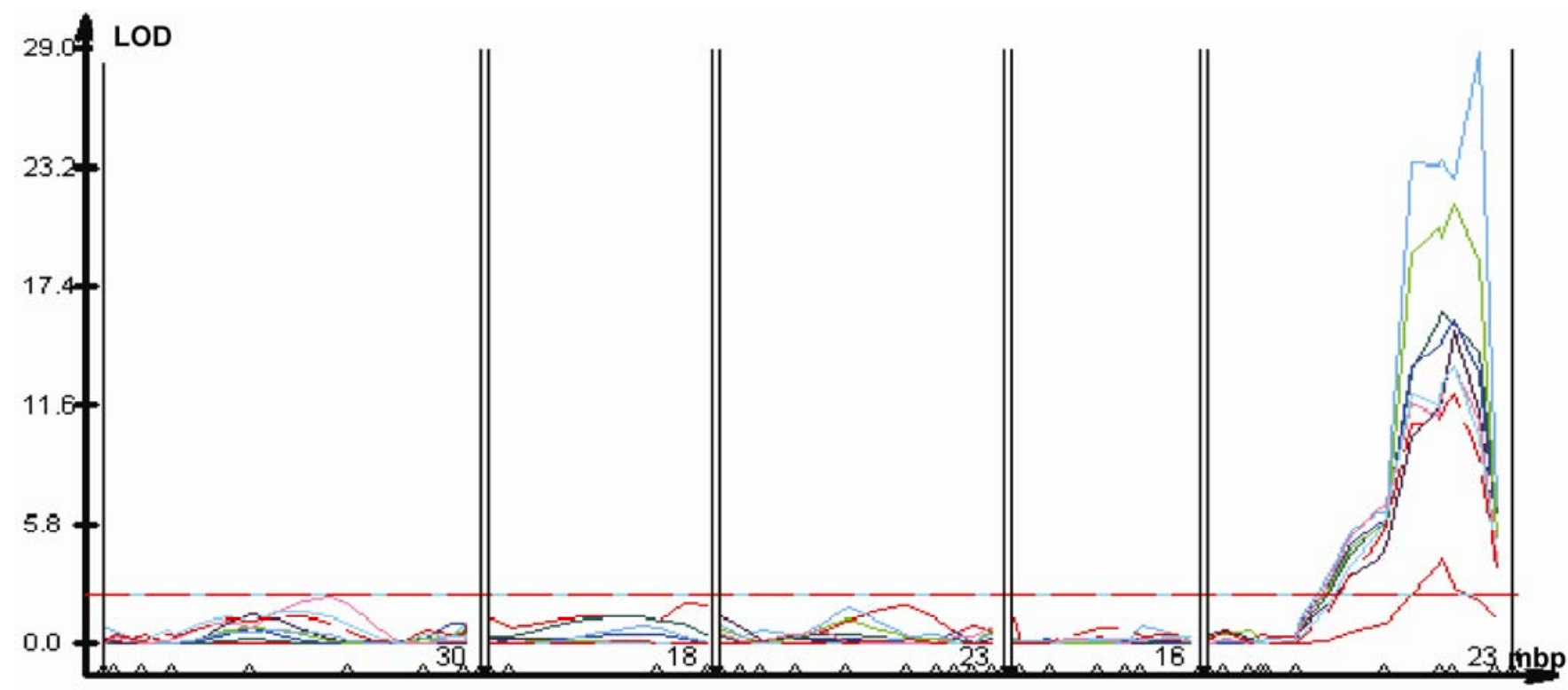

\section{Chromosome $1 \quad$ Chromosome 2 Chromosome $3 \quad$ Chromosome $4 \quad$ Chromosome 5}

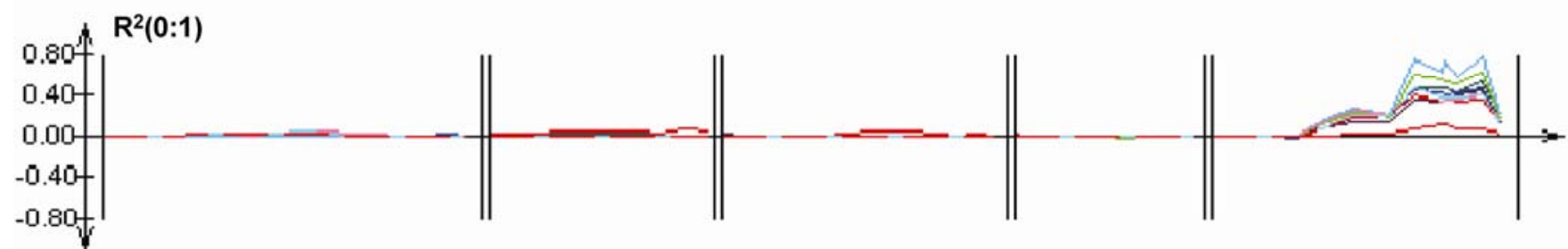

Fig. 6. Quantitative trait loci (QTL) map based on symptom segregation in WRIN lines (recombinant inbred lines from the Ws-3, Nd-1 cross). Nine QTL traits are shown, representing each inoculum concentration $\left(\mathrm{OD}_{600}=0.01,0.05\right.$, or 0.3$)$ scored at 1,2 , and 3 days after inoculation. A large QTL accounting for up to $80 \%$ of symptom variation was identified on chromosome 5 at the position of $F L S 2$. The QTL corresponding to FLS2 is revealed even in lines infiltrated at the lowest inoculum level and scored at 1 day after inoculation $\left(\mathrm{OD}_{600}=0.01\right)$. Logarithm of odds (LOD) scores and a calculated significance threshold of LOD $=2.5$ are displayed across each chromosome. Small triangles indicate marker positions shown in million base pairs (mbp). The highest score was achieved with $\mathrm{OD}_{600}=0.05,3$ days after inoculation. The proportion of variance attributable to each QTL is displayed on the lower graph. 
$\mu \mathrm{g} \mathrm{ml}^{-1}$ ) and, as $20 \%$ glycerol stocks, were stored at $-70^{\circ} \mathrm{C}$. Cultures for inoculation were grown in King's B liquid broth supplemented with appropriate antibiotics. Bacteria were washed in $10 \mathrm{mM} \mathrm{MgCl}$ and were suspended in $10 \mathrm{mM} \mathrm{MgCl}_{2}$ with volume adjusted to reach the desired optical density. Bacterial suspensions were infiltrated into leaves using a needleless syringe after nicking the underside of the leaf. Half-leaf inoculations were performed. Solutions of flagellin peptide in water were infiltrated in the same way. Typically, we used a high concentration of $1 \mu \mathrm{g} \mathrm{ml}^{-1}$ to assess FLS2 activity. Flagellin peptide was synthesized from the sequence of the flg22 consensus in $P$. syringae pv. phaseolicola, TRLSSGLKINSA KDDAAGLQIA. Aniline blue staining for callose was carried out as described by de Torres and associates (2006).

\section{Scoring symptoms.}

Disease symptoms were usually scored at 1, 2, and 3 days after bacterial inoculation. Symptoms were scored on a 12-point scale by comparing the infiltrated area with the noninoculated half of the leaf. The scoring system was as follows: no symptoms (0), very pale yellow (2), pale yellow (4), yellow (6), bright yellow (8), partial collapse (10), total collapse of infiltrated area (12). Intermediate phenotypes were given intermediate scores.

\section{Genotyping.}

F2 populations and WRIN lines were genotyped using a series of CAPS and simple sequence length polymorphism markers detailed in Table 2 . A total of 220 primer combina-
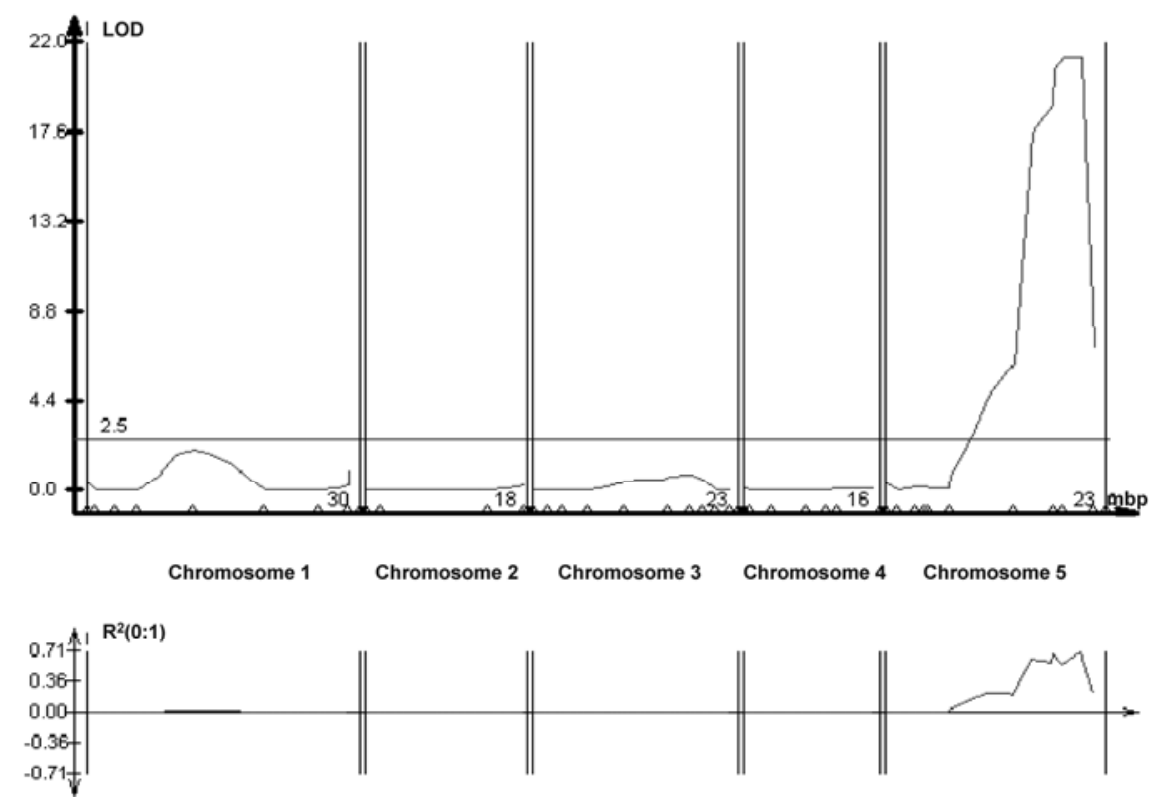

Fig. 7. Quantitative trait loci (QTL) map based on bacterial populations reached in WRIN lines (recombinant inbred lins from the Ws-3, Nd-1 cross). Logarithm of odds (LOD) scores and a calculated significance threshold of LOD $=2.5$ are displayed across each chromosome. Small triangles indicate marker positions shown in million base pairs (mbp). The proportion of variance attributable to each QTL is displayed on the lower graph. A strong QTL accounting for up to $70 \%$ of symptom variation was identified on chromosome 5 at the position of FLS2. A putative QTL was also identified on chromosome 1.

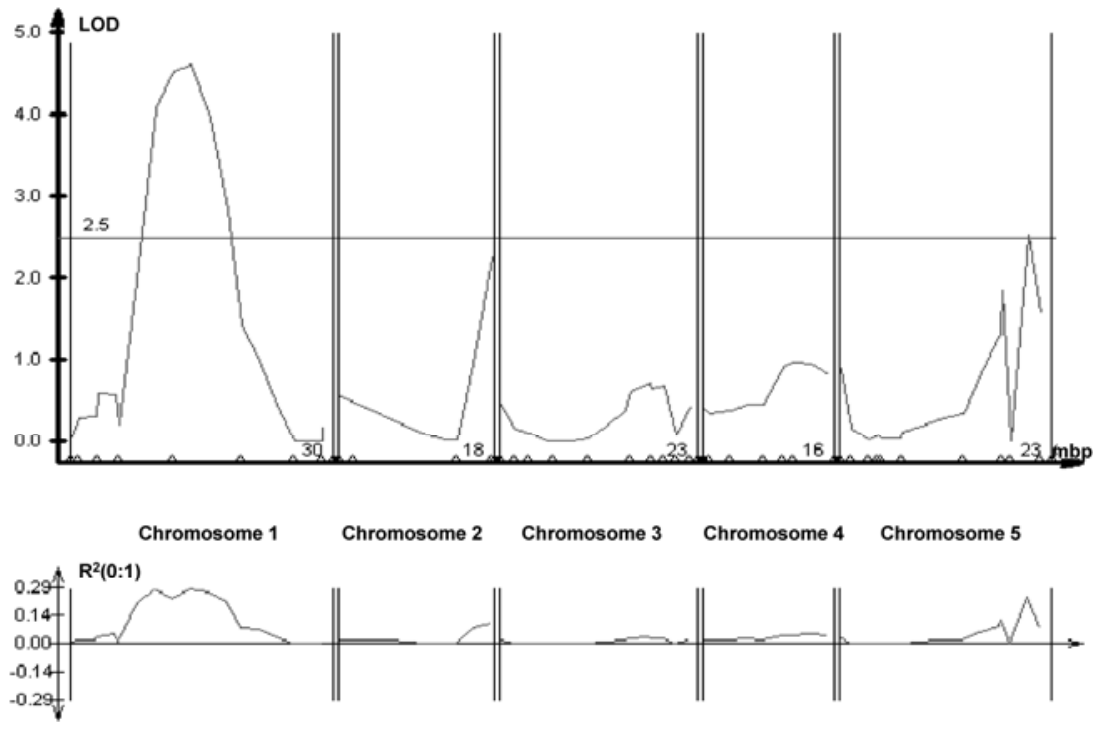

Fig. 8. Quantitative trait loci (QTL) map based on bacterial populations reached in WRIN lines (recombinant inbred lines from the Ws-3, Nd-1 cross) homozygous for FLS2. Logarithm of odds (LOD) scores and a calculated significance threshold of LOD = 2.5 are displayed across each chromosome. Small triangles indicate marker positions shown in million base pairs (mbp). The proportion of variance attributable to each QTL is displayed on the lower graph. A QTL accounting for up to $30 \%$ of variation in population counts was identified on chromosome 1 . 
tions were tested to derive 44 that were polymorphic between Nd-1 and Ws-3. Polymerase chain reaction (PCR) was performed in 50- $\mu 1$ reaction volumes with annealing temperatures of either 50 or $55^{\circ} \mathrm{C}$. PCR product $(30 \mu \mathrm{l})$ was digested with an appropriate restriction enzyme, and the digestion products were resolved in a $3 \%$ agarose Tris-acetate-EDTA gel.

\section{QTL mapping.}

QTL were mapped in RIL using QTL cartographer software. Composite interval mapping was performed for disease symptoms and bacterial populations. For mapping using the WRIN lines, marker segregation data derived from this study were used. The Nd-Col lines were analyzed using marker segregation data previously described by Werner and associates (2005). We confirmed that several markers from the study by Werner and associates (2005) were accurately represented in our seed set.

\section{ACKNOWLEDGMENTS}

We wish to acknowledge financial support from the U.K. Biotechnology and Biological Sciences Research Council. Thanks are also due to M. Kearsey for advice on QTL mapping.

\section{LITERATURE CITED}

Alfano J. R., and Collmer A. 1996. Bacterial pathogens in plants: Life up against the wall. Plant Cell 8:1683-1698.

Banerjee, D., Zhang, Z., and Bent, A. F. 2001. The LRR domain can determine effective interaction between RPS2 and other host factors in Arabidopsis RPS2-mediated disease resistance. Genetics 158:439-450.

Bestwick, C. S., Bennett, M. H., and Mansfield, J. W. 1995. Hrp mutant of Pseudomonas syringae pv. phaseolicola induces cell wall alterations but not membrane damage leading to the hypersensitive reaction in lettuce. Plant Physiol., 108:503-516.

Bock, A., Li, G., Fu, Z. Q., and Alfano, J. 2008. Phytopathogen type III weaponry and their plant targets. Curr. Opin. Plant Biol. 11:396-403.

Boller, T., and Felix G. 2009. A renaissance of elicitors: Perception of microbe-associated molecular patterns and danger signals by pattern-recognition receptors. Annu. Rev. Plant Biol. 60:379-406.

Bomblies, K., and Weigel, D. 2007. Arabidopsis: A model genus for speciation. Curr. Opin. Genet. Dev. 17:500-504.

Brosché, M., Merilo E., Mayer F., Pechter P., Puzõrjova I., Brader G., Kangasjärvi J., and Kollist, H. 2010. Natural variation in ozone sensitivity among Arabidopsis thaliana accessions and its relation to stomatal conductance. Plant Cell Environ. 33:914-925

Buell, C. R., and Somerville, S. C. 1997. Use of Arabidopsis recombinant inbred lines reveals a monogenic and a novel digenic resistance mechanism to Xanthomonas campestris pv. campestris. Plant J. 12:21-29.

Cunnac, S., Lindeberg, M., and Collmer, A. 2009. Pseudomonas syringae type III effectors: Repertoires in search of functions. Curr. Opin. Microbiol. 12:53-60.

Debener, T., Lehnackers, H., M Arnold, M., and Dangl, J. L. 1991. Identification and molecular mapping of a single Arabidopsis thaliana locus determining resistance to a phytopathogenic Pseudomonas syringae isolate. Plant J. 1:289-302.

de Torres M., Mansfield J.W., Grabov N., Brown I. R., Ammouneh H., Tsiamis G., Forsyth A., Robatzek S., Grant M., and Boch J. 2006. Pseudomonas syringae effector AvrPtoB suppresses basal defence in Arabidopsis. Plant J. 47:368-382.

Fan, J., Crooks, C., and Lamb C. J. 2008. High-throughput quantitative luminescence assay of the growth in planta of Pseudomonas syringae chromosomally tagged with Photorhabdus luminescens luxCDABE. Plant J. 53:393-399.

Gimenez-Ibanez, S., Hann, D. R., Ntoukakis, V., Petutschnig, E., Lipka, V.and Rathjen, J. P. 2009. AvrPtoB targets the LysM receptor kinase CERK1 to promote bacterial virulence on plants. Curr. Biol. 19:423-429.
Ham, J. H., Kim, M. G., Lee, S. Y., and Mackey D. 2007. Layered basal defenses underlie non-host resistance of Arabidopsis to Pseudomonas syringae pv. phaseolicola. Plant J. 51:604-616.

He, P., Shan, L., Lin, N. C., Martin, G. B., Kemmerling, B., Nurnberger, T., and Sheen, J. 2006. Specific bacterial suppressors of MAMP signaling upstream of MAPKKK in Arabidopsis innate immunity. Cell 125:563-575

Holub, E. B. 2007. Natural variation in innate immunity of a pioneer species. Curr. Opin. Plant Biol. 10:415-424.

Joardar, V., Lindeberg, M., Jackson, R. W., Selengut, J., Dodson, R., Brinkac, L. M., Daugherty, S. C., DeBoy, R., Durkin, A. S., Giglio, M. G., Madupu, R., Nelson, W. C., Rosovitz, M. J., Sullivan, S., Crabtree, J., Creasy, T., Davidsen, T., Haft, D. H., Zafar, N., Zhou, L. W., Halpin, R., Holley, T., Khouri, H., Feldblyum, T., White, O., Fraser, C. M., Chatterjee, A. K., Cartinhour, S., Schneider, D. J., Mansfield, J., Collmer, A., and Buell, C. R. .2005. Whole-genome sequence analysis of Pseudomonas syringae pv. phaseolicola 1448A reveals divergence among pathovars in genes involved in virulence and transposition. J. Bacteriol. 187:6488-6498.

Kang L., Li, J., Zhao, T., Xiao, F., Tang, X., Thilmony, R., He, S., and Zhou, J. M. 2003. Interplay of the Arabidopsis nonhost resistance gene NHO1 with bacterial virulence. Proc. Natl. Acad. Sci. U.S.A. 100:35193524.

Koornneef, M., Alonso-Blanco, C., and Vreugdenhil, D. 2004. Naturally occurring genetic variation in Arabidopsis thaliana. Annu. Rev. Plant Biol. 255:141-172.

Kover, P. X., and Schaal, B. A. 2002. Genetic variation for disease resistance and tolerance among Arabidopsis thaliana accessions. Proc. Natl. Acad. Sci. U.S.A. 99:11270-11274.

Lu, M., Tang, X., and Zhou, J. M. 2001. Arabidopsis NHO1 is required for general resistance against Pseudomonas bacteria. Plant Cell 13:437447.

Perchepied, L., Kroj, T., Tronchet M., Loudet, O., and Roby, D. 2006. Natural variation in partial resistance to Pseudomonas syringae is controlled by two major QTL in Arabidopsis thaliana. PLoS ONE 1:e123 Published online.

Shan, L., He P., Li, J., Heese, A., Peck, S. C., Nurnberger, T., Martin, G. B., and Sheen, J. 2008. Bacterial effectors target the common signaling partner BAK1 to disrupt multiple MAMP receptor-signaling complexes and impede plant immunity. Cell Host Microbe 4:17-27.

Soylu S., Brown, I. R., and Mansfield, J. W. 2005. Cellular reactions in Arabidopsis following challenge by strains of Pseudomonas syringae: From basal resistance to compatibility. Physiol. Mol. Plant Pathol. 66:232-243.

Weigel D, and Nordborg M. 2005. Natural variation in Arabidopsis How do we find the causal genes? Plant Physiol. 138:567-568.

Werner, J. D, Borevitz, J. O, Warthmann, N., Trainer, G. T, Ecker, J. R, Chory, J., and Weigel, D. 2005. Quantitative trait locus mapping and DNA array hybridization identify an FLM deletion as a cause for natural flowering-time variation. Proc. Natl. Acad. Sci. U.S.A. 102:24602465.

Whalen, M. C., Innes, R. W., Bent, A. F., and Staskawicz, B. J. 1991. Identification of Pseudomonas syringae pathogens of Arabidopsis and a bacterial locus determining avirulence on both Arabidopsis and soybean. Plant Cell 3:49-59.

Yu, G. L., Katagiri, F., and Ausubel, F. M. 1993. Arabidopsis mutations at the RPS2 locus result in loss of resistance to Pseudomonas syringae strains expressing the avirulence gene avrRpt2. Mol Plant-Microbe Interact. 6:434-443.

Zipfel, C., Robatzek, S., Navarro, L., Oakeley, E. J., Jones, J. D., Felix, G., and Boller, T. 2004. Bacterial disease resistance in Arabidopsis through flagellin perception. Nature 428:764-767.

Zipfel, C., Kunze, G., Chinchilla, D., Caniard, A., Jones, J. D., Boller, T., and Felix, G. 2006. Perception of the bacterial PAMP EF-Tu by the receptor EFR restricts Agrobacterium-mediated transformation. Cell $125: 749-760$

\section{AUTHOR-RECOMMENDED INTERNET RESOURCE}

North Caroline State University Bioinformatics Research Center QTL cartographer programs: statgen.ncsu.edu/qtlcart 